\title{
Padronização de reagentes e métodos utilizados na técnica de hemaglutinação para o diagnóstico laboratorial da parvovirose canina
}

\section{Standartization of the reagents and methods of hemagglutination as- say for laboratorial diagnosis of canine parvovirus infection}

Patrícia Santos ${ }^{1}$, Ana Maria Viana Pinto², Rita de Cássia Nasser Cubel Garcia², Norma Vollmer Labarthe ${ }^{3}$, Ledy do Horto dos Santos Oliveira ${ }^{2}$

\section{Resumo}

Amostras fecais de 23 cães com sinais clínicos de parvovirose foram analisadas pela técnica de hemaglutinação seguida de identificação por inibição de hemaglutinação. Foram testados reagentes e várias soluções para um melhor rendimento da técnica. Verificamos que o melhor tampão diluente para as amostras fecais foi a albumina bovina (BABS) pH 9,0. Para hemácias de suínos, utilizamos o tampão VAD (virus adjust diluent) $\mathrm{pH}$ 6,0 . Hemácias obtidas de suínos mostraram-se viáveis por até quatro dias; as de machos deram melhores títulos hemaglutinantes do que as de fêmeas. Após padronização dos reagentes, 23 cães com gastroenterite foram analisados.

Desses, 20 eram positivos para parvovírus canino (CPV); 15 excretavam acima de $10^{10}$ partículas virais $/ \mathrm{ml}$ nas fezes. Foi detectada a presença do parvovírus em seis cães com história de vacinação. Verificamos a presença de CPV em amostras coletadas até quatro dias após o aparecimento dos sinais clínicos. Amostras positivas continuaram estáveis por mais de seis meses, a temperatura de $4^{\circ} \mathrm{C}$. A produção de soro anti-parvovírus necessário para o teste de inibição da hemaglutinação (HI) tem melhor rendimento se o esquema de inoculação incluir a administração do vírus vacinal por via intravenosa, com reforço peritoneal. Títulos hemaglutinantes menores que $1 / 8$ foram considerados negativos para CPV. Titulos maiores ou iguais a 1/8 foram testados por $\mathrm{HI}$.

Palavras chaves: parvovírus canino; hemaglutinação; diagnóstico viral

\section{Introdução}

A parvovirose canina é uma doença infecciosa emergente, tendo aparecido mundialmente e com conseqüên- cias fatais no final da década de 70 . No Brasil, surgiu na década de 80. A princípio atingia animais de todas as idades, provocando miocardite em recém natos e enterite em cães jovens; atualmente a doença restringe-se a fiIhotes. O agente etiológico pertence à família Parvoviridae, gênero Parvovírus. A partícula viral é constituída de ADN de fita simples, capsídeo de simetria icosaédrica, sem envelope, medindo cerca de 20-23 nm de diâmetro (Else, 1980).

O parvovírus canino (CPV) foi denominado de CPV-2, a fim de diferenciá-lo do vírus mínimo de cão (MVC ou CPV-1) descrito em 1967 naAlemanha (Binn et al., 1970) e que não está associado a casos de diarréia.

O CPV é antigênico e geneticamente similar ao vírus da panleucopenia felina (FPV) e ao vírus da enterite do mink, sendo portanto considerado uma variante do FPV (Pollock e Coyne, 1990; Parrish, 1994).

Desde que emergiu em 1978 como um novo patógeno de cães o CPV continua a evoluir. Parrish et al. (1985) utilizando anticorpos monoclonais específicos e enzimas de restrição observaram que as amostras que circularam nos Estados Unidos entre 1978 e 1980 podiam ser distinguidas das anteriores pela reatividade com anticorpos monoclonais específicos e por diferenças no mapa de restrição. Essa nova variante (CPV-2a) rapidamente substituiu o tipo anterior em circulação e passou a prevalecer na população canina. A partir de 1984 surgiu uma nova variante, o CPV-2b; apenas $10-30 \%$ das amostras de CPV isoladas na Europa e Estados Unidos atualmente são do tipo 2a (Parrish et al., 1985; Parrish, 1994). Acredita-se que estas novas variantes de CPV sejam mais adapatadas à replicação em cães, facilitando a disseminação do vírus na população canina (Parrish et al., 1985). O CPV-2 é transmitido, principalmente, por via oro-fecal. Fezes ou fluidos contaminados constituem a fonte primária da infecção da parvovirose canina. A eliminação

\footnotetext{
Trabalho realizado com recursos de Laboratórios Pfizer Ltda., Divisão Agropecuária, Guarulhos, São Paulo, Brasil

1 Graduanda do curso de Medicina Veterinária, UFF

${ }^{2}$ Departamento de Microbiologia e Parasitologia, Instituto Biomédico, Universidade Federal Fluminense, UFF, Rua Prof. Ernani Melo 101, 24210 130 Niterói, RJ, Brasil

${ }^{3}$ Departamento de Patologia e Clínica, Faculdade de Veterinária, UFF
} 
ativa do vírus nas fezes ocorre nas primeiras duas semanas após a infecção e, uma vez eliminadas, as partículas de CPV-2 são infectantes por até seis meses. A alta concentração de vírus eliminados pelos animais infectados, a resistência do CPV ao meio ambiente e a ausência de anticorpos anti-CPV-2 na população canina, antes de 1978, contribuíram para a disseminação global do vírus (Pollock e Coyne, 1993). Atualmente, vacinas de vírus atenuados ou inativados são utilizadas no controle e prevenção da infecção. As vacinas atenuadas podem contribuir também para proteger os cães não vacinados, seja por disseminação natural no ambiente, seja por reduzir a circulação do tipo selvagem (Fenner et al., 1993).

Como os sinais clínicos da infecção podem ser confundidos com a forma entérica de outras doenças infecciosas ou parasitárias, o diagnóstico definitivo só pode ser feito através da demonstração do vírus ou do antígeno viral na amostra clínica.

O diagnóstico laboratorial para detecção do CPV deve ser utilizado na confirmação de casos duvidosos, investigação epidemiológica, aparecimento de cepas mais virulentas e avaliação de vacinas. Diversos métodos tais como microscopia eletrônica, hemaglutinação (HA), isolamento viral e ELISA estão disponíveis para a confirmação de um diagnóstico de enterite causada por CPV-2. As reações de imunofluorescência, imunoperoxidase e métodos de imunoensaio podem ser usados para identificar o vírus em amostras de tecidos. Todos são adequados para o diagnóstico dos casos agudos, dependendo da concentração de vírus e da colheita do material em período adequado: A resposta imune, iniciada de quatro a cinco dias após a infecção, inibe a presença do vírus que só pode ser detectado quatro a sete dias após o início dos sinais clínicos (Pollock e Carmichael, 1990).

A detecção do CPV por HA apresenta bons resultados. O teste de $H A$, seguido de inibição de hemaglutinação $(\mathrm{HI})$, não mede a infectividade mas é um dos testes mais usados para identificar as partículas virais, sendo o melhor método para triagem quando há um grande número de amostras. O CPV-2 aglutina hemácias de porco e de macacos Rhesus e depende de um pH definido e soluções diluentes com alta força iônica (Appel et al., 1979; Angelo, 1988).

Este trabalho teve como objetivos a padronização de soluções e reagentes necessários para a realização do teste de HA seguida da identificação por $\mathrm{HI}$, com a finalidade de detectar o CPV-2 em amostras fecais de cães com sinais clínicos de parvovirose.

\section{Material e Métodos}

Visando obter rendimento ideal das reações de $\mathrm{HA} \mathrm{e}$ $\mathrm{HI}$, testamos como diluente do antígeno viral os tampões solução salina fosfato (PBS) nos pHs 6,8 e 7,0, solução salina borato (BBS) e o tampão BBS contendo $0,2 \%$ de albumina bovina (BABS) pH 9,0. Como antígeno da rea- ção, foi utilizada a vacina Parvoguard® (Laboratório Solvay Saúde Animal Ltda.), com concentração de $10^{6,5}$ partículas virais/ml, tendo sido testado nas diluições de 1/10 e 1/100.

Para seleção dos suínos doadores de hemácias, foram utilizados oito porcos (cinco machos e três fêmeas) de uma mesma ninhada. O sangue foi coletado em solução de Alsever e a suspensão mantida a uma temperatura de $4^{\circ} \mathrm{C}$ por $24 \mathrm{~h}$, tempo necessário para a sedimentação das hemácias (Carmichael et al., 1980). Após três lavagens das hemácias em tampão VAD (virus adjust diluent) $\mathrm{pH} 6,0$, foi preparada uma solução de hemácias a $0,5 \%$ no mesmo tampão. O título hemaglutinante foi obtido por diluição das hemácias em VAD. A viabilidade das hemácias, no período de 2, 4 e 7 dias de estocagem a $4^{\circ} \mathrm{C}$ após a colheita foi testada por HA.

Para confecção do anti-soro heterólogo contra CPV-2 em coelhos, foram preparados dois protocolos de imunização. No protocolo 1, um coelho foi inoculado por via intramuscular profunda com $1 \mathrm{ml}$ de vacina diluída a 1:100. O sangue foi coletado na segunda e quinta semanas após a inoculação e o soro foi separado por centrifugação a $2000 \mathrm{rpm}$ por $10 \mathrm{~min}$. A presença de anticorpos foi testada pela técnica de HI. No protocolo 2, um coelho foi inoculado por via intravenosa, com $0,3 \mathrm{ml}$ de vacina não diluída e, uma semana depois, com $0,7 \mathrm{ml}$ por via intraperitoneal. Oito dias após, o sangue foi coletado por via intravenosa e processado pela forma descrita. Um mês depois da primeira inoculação, foi feito um reforço com 1 $\mathrm{ml}$ da vacina diluída a 1:10 por via intraperitoneal. Dez dias após foi feita sangria branca no coelho.

A fim de se evitar reações inespecíficas no teste de $\mathrm{HI}$, o soro foi inicialmente inativado a $56^{\circ} \mathrm{C}$ por $30 \mathrm{~min}$, tratado por solução de caolim a $25 \%$ em BABS e a seguir por uma suspensão de hemácias de porco a $50 \%$ em VAD. Para verificar o título antiparvovírus dos soros, eles foram testados por $\mathrm{HI}$, utilizando-se quatro unidades hemaglutinantes (UHA) do antígeno por $0,25 \mathrm{ml}$ de hemácias a $0,5 \%$.

Com o anti-soro padronizado, verificamos a especificidade das reações positivas para HA. As amostras fecais positivas foram testadas para $\mathrm{HI}$ em uma concentração de 4 UHA $0,25 \mathrm{ml}$ contra o soro antiparvovírus inicialmente diluído a 1/10. Foi usado, como controle da reação, o vírus vacinal na mesma concentração. Amostras com títulos de HA menor ou igual a $1 / 8$ foram consideradas negativas. Amostras com títulos superiores a 1/ 8 foram testadas para HI.

A detecção de parvovírus foi iniciada com a coleta de especimens fecais de 23 cães, com até seis meses de idade, que apresentavam diarréia e/ou vômito, na Policlínica da Faculdade de Veterinária da UFF e em clínicas particulares. As amostras foram colhidas diretamente do reto, com um tubo de polietileno, no período de abril a dezembro de 1995. O material foi colocado em frasco estéril e mantido sob refrigeração. Por ocasião da coleta, cada animal foi cadastrado em ficha própria contendo 
nome e endereço do proprietário, nome e idade do animal, sexo, local e data de coleta da amostra fecal, período entre o aparecimento de sinais clínicos e a coleta das fezes e histórico de vacina, tendo sido considerado cão vacinado o animal que recebeu a vacina antiparvovírus aos dois, três e quatro meses de idade. Os espécimens foram testados por HA seguida da contraprova por HI. Para verificação da estabilidade do vírus nas amostras fecais, estas foram mantidas em geladeira a $4^{\circ} \mathrm{C}$ e retestadas aos $30,60,90$ e 180 dias após a colheita.

\section{Resultados}

Entre os tampões utilizados para diluir o antígeno, 0 que deu melhores resultados foi o BABS $\mathrm{pH} 9,0$ que combinado ao VAD pH 6,0 manteve as hemácias viáveis. Com os tampões PBS pH 6,8 e pH 7,0 observou-se aglutinação das hemácias na ausência do vírus. Para diluição das hemácias, o tampão VAD pH 6,0 foi adequado, pois manteve a estabilidade das mesmas durante o tempo de reação. No teste dos componentes da reação, a melhor diluição inicial da vacina foi de $1 / 100$. A vacina inicialmente diluída a $1 / 10$ apresentou positividade até diluições de $1 / 800$, consumindo mais material e tempo para a execução da técnica.

Foram escolhidos os suínos cujas hemácias deram maior título hemaglutinante. Três fêmeas apresentaram hemácias com títulos hemaglutinantes de 1/100, 1/200 e $1 / 400$. Outras duas e um macho deram aglutinação inespecífica. Dois machos que apresentaram hemácias com título de $1 / 600$ e 1/800, foram os escolhidos como fonte de hemácias.

As hemácias devem ser utilizadas até quatro dias após a coleta. Os melhores títulos hemaglutinantes foram observados nesse período. Após quatro dias, os títulos declinam gradativamente. Além de sete dias, as hemácias se tornam auto-aglutináveis.

Pelo teste de HI, observamos que o primeiro esquema de imunização no coelho não induziu anticorpos detectáveis. No segundo protocolo, em que utilizamos inoculação intravenosa com posterior reforço intraperitoneal, encontramos um título de 1/320.

Os resultados obtidos na detecção de CPV em nossa amostragem de fezes caninas com sinais de parvovirose estão sumarizados na Tabela. Das 23 amostras analisadas, 20 eram positivas para CPV pelo teste de HA e confirmadas por HI. Como a população estudada tinha predominância de machos, não foi possível associar relação significativa entre sexo e presença de CPV.

Seis cães com história de vacinação foram positivos para CPV (Tabela). Esses cães foram identificados como Fila Brasileiro, Rottweiler, SRD, Doberman, Pastor/ Doberman e Husky Siberiano. Com exceção do Rottweiler,

Tabela 1 - Resultado do teste de hemaglutinação para parvovírus canino em 23 cães com gastroenterite

\begin{tabular}{|c|c|c|c|c|c|c|}
\hline Amostra no. & Idade(meses) & Sexo & Coleta/ dias ${ }^{a}$ & Resultado & * & Raça \\
\hline 1 & 3 & $M$ & 3 & + & 23 & Fila Brasileiro \\
\hline 2 & 4 & $M$ & 5 & - & SV & SRD \\
\hline 3 & 5 & $\mathrm{~F}$ & $\mathrm{i}$ & - & 24 & Coker S. \\
\hline 4 & 3 & $\mathrm{~F}$ & 3 & + & SV & SRD \\
\hline 5 & $i$ & $\mathrm{i}$ & $\mathrm{i}$ & + & SV & i \\
\hline 6 & 2 & $M$ & 2 & + & SV & SRD \\
\hline 7 & 4 & $F$ & 2 & + & SV & SRD \\
\hline 10 & $\mathrm{i}$ & i & $\bar{i}$ & + & SV & $i$ \\
\hline 11 & 4 & $M$ & 2 & + & SV & Terrier \\
\hline 13 & 6 & $M$ & 2 & + & SV & SRD \\
\hline 14 & 4 & $M$ & 3 & + & 9 & Rottweiler \\
\hline 27 & 4 & $\mathrm{~F}$ & $\mathrm{i}$ & + & SV & Poodle \\
\hline 28 & 4 & $M$ & 2 & + & SV & SRD \\
\hline 29 & 3 & $M$ & 1 & + & SV & Pastor Alemão \\
\hline 31 & 2 & $M$ & 3 & + & 26 & SRD \\
\hline 34 & 2 & $M$ & 3 & + & SV & SRD \\
\hline 35 & 4 & $M$ & 1 & + & SV & Basenji \\
\hline 37 & 3 & $M$ & 1 & + & SV & SRD \\
\hline 38 & $\mathrm{i}$ & i & $\mathrm{i}$ & - & SV & $\mathrm{i}$ \\
\hline 39 & 4 & $M$ & 2 & + & 63 & Dobberman/ Weimanner \\
\hline 40 & 5 & $\mathrm{~F}$ & 3 & + & 93 & Pastor/ Doberman \\
\hline 41 & 3 & $\mathrm{~F}$ & 2 & + & SV & SRD \\
\hline 44 & 3 & $M$ & 4 & + & 11 & Husky Siberiano \\
\hline
\end{tabular}

SV: sem vacinação; *: no. de dias após a última dose de vacina recebida e a coleta das amostras; i: ignorado; a: dias entre o aparecimento dos sinais clínicos e a coleta da amostra. As amostras que não foram processadas estavam contaminadas. 
os outros cães não apresentavam esquema de vacinação completa. O intervalo entre a data de aplicação da última vacina contra CPV e o aparecimento dos sinais variou de 9 a 92 dias.

$\mathrm{Na}$ Figura são apresentados os títulos de HA das amostras analisadas. Títulos maiores que $1 / 8192$ não foram mostrados. Podemos observar que $75 \%$ dos cães positivos para CPV excretavam, na época da coleta das fezes, cerca de $10^{10}$ partículas virais por $\mathrm{ml}$, infecciosas ou não. A presença do vírus nas amostras fecais continuava estável e detectável em concentrações constantes por até seis meses após a coleta.

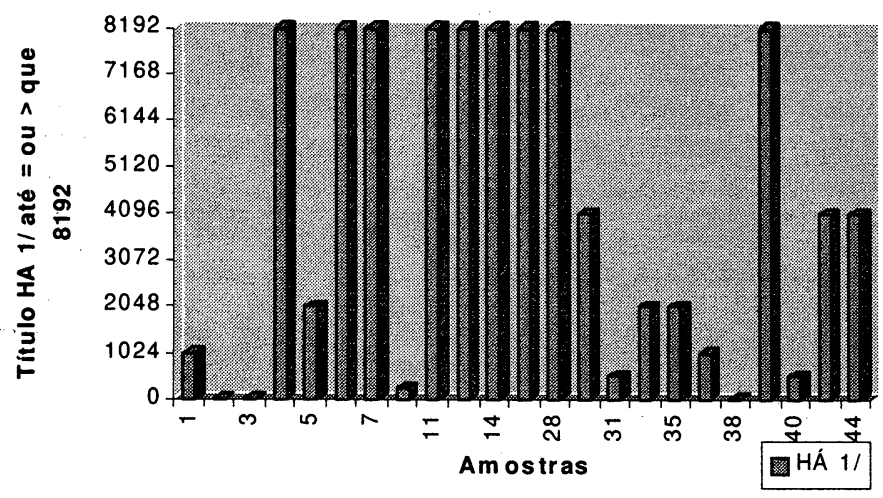

Presença do parvovírus canino em amostras fecais caninas.

\section{Discussão e Conclusões}

A técnica de $\mathrm{HA}$, com contraprova de $\mathrm{HI}$, é uma técnica comum e bastante eficaz na confirmação de diagnóstico de CPV em amostras fecais suspeitas. Mohan et al. (1993) verificaram que os testes ELISA e HA foram usados para detectar antígenos nas fezes de 42 cães apresentando gastrenterite hemorrágica. Do resultado das amostras testadas por ELISA, 19 foram falso positivos, 14 positivos e 6 fracamente positivos. Um foi duvidoso e 2 foram negativos. Os resultados dos HA foram semelhantes. Houve, portanto, $100 \%$ de correlação entre o teste ELISA e o HA.

Em um estudo realizado por Duringon et al. (1987), foram comparadas as técnicas de HA, o isolamento do vírus em culturas celulares, a reação de imunoeletromosforese e imunomicroscopia eletrônica. A comparação entre os quatro métodos demonstrou ser a reação de HA mais eficiente do que as outras técnicas adotadas. Essa, entretanto, além de exigir a constante obtenção de hemácias frescas de suínos ou de macacos Rhesus para a sua realização, tem a desvantagem de apresentar resultados inespecíficos para o CPV em amostras com títulos hemaglutinantes baixos. Por isso há necessidade da realização do teste de HI para confirmação do diagnóstico (Pollock e Carmichael, 1990).
Após testarmos vários reagentes e soluções, concluímos que para uma boa resolução do HA são necessários tampões que mantenham o pH 6,0, ótimo para a reação, uma vez que $\mathrm{o} \mathrm{pH}$ abaixo de 5,5 promove a autoaglutinação espontânea das hemácias de porco. Este fato ocorre também com hemácias colhidas há mais de quatro dias, o que dificulta o trabalho, pois há necessidade de uma constante obtenção de hemácias frescas.

Com os reagentes padronizados, testamos a presença do CPV em 23 cães com sinais de gastrenterite por CPV. Apesar de haver um teste comercial de ELISA para diagnóstico laboratorial de CPV, a maioria das clínicas veterinárias do Estado do Rio de Janeiro não tem como rotina confirmar o diagnóstico de CPV, talvez devido a seu custo. Embora seja pequena nossa amostragem, e por isto não nos preocupamos em dar um tratamento estatístico ao trabalho, verificamos que $87 \%$ dos cães analisados adoeceram por parvovírus, inclusive seis cães com história de vacinação (Tabela). Considerando-se o intervalo entre o aparecimento dos sinais clínicos e a data da última ou única dose de vacina, que excedia a dez dias, podemos sugerir que os seis cães tinham sido infectados pelo vírus selvagem.

Para que o resultado de detecção de CPV-2 nas amostras fecais não se apresente falso negativo, é necessário que a coleta seja feita precocemente durante o curso da infecção. A resposta imune para esse vírus se generaliza rapidamente, iniciando-se quatro a cinco dias após a infecção. Conseqüentemente o vírus só pode ser detectado nas fezes durante um curto período de tempo (três a quatro dias) após o início dos sinais clínicos (Pollock e Carmichael, 1990). Na amostragem apresentada, o intervalo entre o aparecimento dos sinais e amostra positiva foi de no máximo quatro dias (Tabela).

Sabe-se que o CPV-2 é muito resistente ao meio ambiente, permanecendo estável por até seis meses fora da célula, se mantido a $4^{\circ} \mathrm{C}$ (Corrêa e Corrêa, 1992). As amostras positivas testadas no decorrer do período em que trabalhamos (cerca de seis meses) mantiveram sua positividade.

A especificidade da HA depende da contraprova por HI. Para execução desse teste, foi necessário produzir soro imune em nosso laboratório. Utilizando dois protocolos para inoculação do vírus vacinal em coelho, obtivemos melhores resultados com inoculação por via intravenosa e uma dose de reforço, por via intraperitonial, após intervalo de uma semana.

Em um estudo preliminar para identificar os vírus que causam diarréia hemorrágica em cães, Mehnert et al. (1996) observaram que em 1115 amostras fecais obtidas de animais doentes, de diferentes partes do país, no periodo de 1991 a 1996, o CPV ainda é o responsável pelo maior número de casos. No Rio de Janeiro, surtos da doença parecem ocorrer durante o ano com variações sa- 
zonais, mas a prevalência de gastrenterites por CPV-2 ainda não foi determinada. Considerando que, em nosso trabalho, $87 \%$ dos cães investigados estavam infectados por CPV, concluímos ser importante dar continuidade a uma avaliação epidemiológica. A padronização do teste de HA resultou em melhor sensibilidade da técnica. Assim, possibilitará maior rendimento no estudo das infecções por esse vírus no Rio de Janeiro.

\section{Abstract}

Standartization of the reagents ano methods of hemagglutination assay for laboratorial diagnosis of canine parvovirus infection

Faecal samples from 23 puppies with clinical signs of parvovirus were evaluated by hemagglutination (HA) assay followed by hemagglutination inhibition $(\mathrm{HI})$ assay. We have started testing several reagents and solutions to attain the best efficiency of the assay. We have verified that the best diluting buffer for faecal samples was the bovin albumin, $\mathrm{pH}$ 9.0. The virus adjust diluent (VAD) $\mathrm{pH} 6.0$ was the buffer used for porcine red blood cells. The red blood cells showed to be viable up to four days and the male swine red blood cells gave better hemagglutinating titres. After standartizing the reagents, 23 dogs with gastrinteritis signals were tested. From these, 20 were positive to canine parvovirus (CPV). Fifteen puppies eliminated more than $10^{10}$ viral particles/ml. Among those, six puppies had been vaccinated. We have detected $C P V$ in faeces which have been colected until four days after the clinical signs have begun. Positive samples kept viral antigen for at least six months at $4^{\circ} \mathrm{C}$. In order to have an parvovirus antiserum to the inhibition hemagglutination assay the best protocol was to use intravenous inoculation with a intraperitoneal booster. Hemaggutination titers lower than $1 / 8$ were considered to be negative for CPV. Titers of $1 / 8$ or higher were confirmed by $\mathrm{HI}$.

Key words: canine parvovirus; hemagglutination; viral diagnosis

\section{Referências bibliográficas}

Angelo MJO 1988. Isolamento de parvovirus no Brasil. Rev Fac Med Vet Zoot Univ São Paulo 25(1): 123-134.

Appel MJG, Scott FW, Carmichael LE 1979. Isolation and immunization studies of a canine parvo-like virus from dogs with haemorragic enteritis. Vet Rec 105: 156-159.

Bin LN, Lazer EC, Eddy GA, Kajima T 1970. Recovery and characterization of a minute virus of canines. Infect Immun 1: 503-508.

Carmichael E, Joubert JC, Pollock RVH 1980. Hemagglutination by canine parvovirus: Serologic studies and diagnostic application. Am J Vet Res 41(5): 784-791.

Cornachia G 1993. La parvovirose del cane. Objetiv Vet 6: 9-11.

Corrêa WM, Corrêa CNM 1992. Gastroenterite canina por parvovírus, p. 551-559. In Enfermidades Infecciosas dos Animais Domésticos. Editora Médica e Científica, Rio de Janeiro.

Duringon EL, Ângelo MJO, Jerez JO 1987. Comparação entre as reações de hemaglutinação (HA), isolamento do vírus em cultura celulares (CC), imunoeletroforese (IEOF) e imunomicroscopia eletrônica (IME) para o diagnóstico etiológico de parvovirose canina. Rev Microbiol 1:.205-210.

Else RW 1980. Fatal haemorrhagic enteritis in a puppy associated with a parvovirus infection. Vet Rec 106: 14-5.

Fenner FJ, Gibbs EPJ, Murphy FA, Rott R, Studdent MJ, White DO 1973. Immunization against viral disease, p. 241263. In Veterinary Virology, Academic Press.

Mehnert DU, Monezi TA, Prado MA, Harso CM, Cavaleiro MJ, Queiroz APS, Müller NG, Angelo MGO 1996. Canine gastroenteritis in Brazil. Preliminary reults of a viral etiological study. VIII Encontro Nacional de Virologia, São Lourenço, MG, p. 43.

Mohan R, Naurival DC, Sigh KB 1993. Detection of canine parvo virus in faeces, using a parvo virus ELISA test kit. Indian Vet J 70: 301-303.

Parrish CR 1994. The emergence an evoluation of canine parvovirus example of recent host mutation. Seminars in Virology 5: 121-132.

Parrish CR, O'Connel PH, Everman JF, Carmichael E 1985. Natural variation of canine parvovirus. Science 230: 10461048.

Pollock, RVH, Carmichael LE 1990. Canine viral enteritis, p. 268-281. In C Greebe Infectous Diseases of the Dog and Cat. WB Saunders, Philadelphia.

Pollock RVH, Coyne MJ 1993. Gastroenterology: canine parvovirus. Vet Clinics SmallAnimal Practice 23(3): 555-569. 